\title{
ANALISIS PEMASARAN AGROINDUSTRI RUMAH TANGGA GULA KELAPA DI KECAMATAN WULUHAN KABUPATEN JEMBER
}

\section{MARKETING AGROINDUSTRY MARKETING ANALYSIS OF COCONUT SUGAR IN SUB DISTRICT JEMBER REGENCY}

\author{
Claresta Febriana Putri ${ }^{1}$ ), Henik Prayuginingsih ${ }^{2)}$, dan Syamsul Hadi ${ }^{2)}$ \\ $\left.{ }^{1}\right)$ Fakultas Pertanian, Program Studi Agribisnis, UM Jember \\ ${ }^{2}$ ) Dosen Fakultas Pertanian, Program Studi Agribisnis, UM Jember \\ e-mail: clarestafe@gmail.com
}

\begin{abstract}
ABSTRAK
Tujuan dari penelitian adalah untuk mengetahui:1) pola saluran pemasaran, 2) marjin pemasaran, dan 3) efisiensi pemasaran gula kelapa tiap skala usaha di Kecamatan Wuluhan Kabupaten Jember. Penelitian menggunakan metode deskriptif dan survey dengan lokasi penelitian dipilih secara sengaja (purposive method). Pengambilan sampel dilakukan menggunakan metode Snowball Rolling. Analisis data menggunakan analisis deskriptif, dan margin pemasaran ditinjau dari berbagai skala usaha. Hasil penelitian menunjukkan bahwa: 1) Saluran pemasaran terdiri atas saluran nol tingkat digunakan oleh $11,11 \%$ pengrajin dari skala kecil, saluran satu tingkat digunakan oleh $84,44 \%$ dari pengrajin skala kecil dan menengah, dan saluran tiga tingkat digunakan oleh $4,44 \%$ pengrajin dari skala besar. 2) Margin saluran pemasaran nol tingkat Rp. 0,-/kg, satu tingkat Rp. 700,-/kg dan tiga tingkat Rp. 1575,-/kg. 3) Seluruh saluran pemasaran efisien dengan share harga $100 \%$ pada saluran nol tingkat, 93,13\% pada saluran satu tingkat dan $87,40 \%$ pada saluran tiga tingkat.
\end{abstract}

Kata Kunci : Agroindustri Gula Kelapa, Saluran Pemasaran, Marjin Pemasaran, dan Efisiensi Pemasaran.

\section{ABSTRACT}

The purpose of this research is to know: 1) marketing channel pattern, 2) marketing margin, and 3) marketing efficiency of palm sugar per business scale in Wuluhan sub-district, Jember regency. The research used descriptive method and survey with purposive method. Sampling is done using Snowball Rolling method. Data analysis uses descriptive analysis, and marketing margin is viewed from various business scale. The results show that: 1) The marketing channel consists of zero channel level used by $11.11 \%$ of craftsmen from small scale, one level channel used by $84.44 \%$ of small and medium-scale craftsmen, and the three-tier channel is used by $4.44 \%$ of artisans of a large scale. 2) Margin marketing channel zero rate Rp. O, - / kg, one level Rp. 700, - / kg and three levels Rp. 1575, - / kg. 3) All marketing channels are efficient with price share $100 \%$ on zero channel rate, $93.13 \%$ on one level channel and $87.40 \%$ on triple channel.

Keywords: Coconut Sugar Agroindustry, Marketing Channel, Marketing Margin, and Marketing Efficiency.

\section{PENDAHULUAN}

Indonesia merupakan negara agraris yang sebagian besar penduduknya menggantungkan hidup pada sektor pertanian. Selain sebagai penyedia lapangan pekerjaan, sektor pertanian juga berperan sebagai penyumbang devisa negara serta sebagai penyedia kebutuhan pangan dalam negeri. Produk pertanian mempunyai peranan penting bagi masyarakat. Salah satunya adalah sebagai bahan baku dalam kegiatan industri, baik industri besar, industri menengah, industri kecil maupun industri rumah tangga.

Pengolahan hasil pertanian bertujuan untuk mengawetkan, menyajikan produk menjadi lebih siap dikonsumsi serta meningkatkan kualitas produk sehingga dapat disajikan dalam bentuk yang lebih baik dan dapat lebih memberikan kepuasan kepada konsumen. Terdapat banyak produk pertanian yang sangat potensial untuk ditingkatkan nilainya sehingga dapat memperoleh harga jual yang lebih tinggi. 
Sebagai penggerak pembangunan pertanian, agroindustri diharapkan dapat memainkan peranan penting kegiatan pembangunan daerah dalam sasaran pemerataan pembangunan ekonomi. Keberadaaan agroindustri di pedesaan diharapkan dapat meningkatkan permintaan terhadap komoditas pertanian, karena sektor agroindustri berperan dalam mengubah produk pertanian menjadi barang yang lebih berguna bagi kebutuhan masyarakat.

Keadaan alam Indonesia yang beriklim tropis membuat tanaman kelapa banyak tumbuh dan berkembang di Indonesia khususnya di sepanjang daerah pantai, karena tanaman kelapa dapat tumbuh dengan baik di lingkungan yang bersuhu kurang lebih $27^{\circ} \mathrm{C}$ dan pada ketinggian tempat 0 - 450 meter dpl.

Tabel 1. Luas Panen, Produksi dan Produktivitas Perkebunan Kelapa Berdasarkan Kecamatan di Kabupaten Jember Tahun 2014

\begin{tabular}{|c|c|c|c|c|}
\hline No & Kecamatan & $\begin{array}{l}\text { Luas Area } \\
(\mathrm{Ha})\end{array}$ & $\begin{array}{l}\text { Produksi } \\
\quad(\mathrm{kw})\end{array}$ & $\begin{array}{l}\text { Produktivitas } \\
(\mathrm{kw} / \mathrm{ha})\end{array}$ \\
\hline 1 & Kencong & 467,67 & 3686,18 & 7,95 \\
\hline 2 & Gumukmas & 420,86 & 3316,36 & 7,88 \\
\hline 3 & Puger & 792,33 & 6616,00 & 8,35 \\
\hline 4 & Wuluhan & 940,84 & 7771,37 & 8,26 \\
\hline 5 & Ambulu & 702,78 & 5938,47 & 8,45 \\
\hline 6 & Tempurejo & 298,80 & 2318,69 & 7,76 \\
\hline 7 & Silo & 231,70 & 1888,35 & 8,15 \\
\hline 8 & Mayang & 318,54 & 2468,71 & 7,75 \\
\hline 9 & Mumbulsari & 353,91 & 2802,95 & 7,92 \\
\hline 10 & Jenggawah & 549,76 & 4101,17 & 7,46 \\
\hline 11 & Ajung & 65,76 & 468,21 & 7,12 \\
\hline 12 & Rambipuji & 422,10 & 3478,08 & 8,24 \\
\hline 13 & Balung & 340,13 & 2503,34 & 7,36 \\
\hline 14 & Umbulsari & 418,49 & 3167,95 & 7,57 \\
\hline 15 & Semboro & 75,36 & 516,97 & 6,68 \\
\hline 16 & Jombang & 123,40 & 869,97 & 7,05 \\
\hline 17 & Sumberbaru & 288,49 & 2244,42 & 7,78 \\
\hline 18 & Tanggul & 170,58 & 1252,03 & 7,34 \\
\hline 19 & Bangsalsari & 316,60 & 2403,01 & 7,59 \\
\hline 20 & Panti & 116,42 & 873,17 & 7,50 \\
\hline 21 & Sukorambi & 131,39 & 885,57 & 6,74 \\
\hline 22 & Arjasa & 139,65 & 1020,87 & 7,31 \\
\hline 23 & Pakusari & 65,44 & 484,27 & 7,40 \\
\hline 24 & Kalisat & 256,24 & 1921,82 & 7,50 \\
\hline 25 & Ledokombo & 308,19 & 2388,45 & 7,75 \\
\hline 26 & Sumberjambe & 109,46 & 890,97 & 8,14 \\
\hline 27 & Sukowono & 167,75 & 1306,80 & 7,79 \\
\hline 28 & Jelbuk & 151,90 & 1139,22 & 7,50 \\
\hline 29 & Kaliwates & 49,23 & 350,03 & 7,11 \\
\hline 30 & Sumbersari & 19,35 & 132,52 & 6,85 \\
\hline 31 & Patrang & 202,03 & 1519,28 & 7,52 \\
\hline \multicolumn{2}{|c|}{ Jumlah } & 9011,15 & 70725,20 & 7,85 \\
\hline
\end{tabular}

Sumber: Badan Pusat Statistik Jember (2015).

Tabel 1 menunjukkan bahwa produksi kelapa paling tinggi terdapat di Kecamatan Wuluhan yakni sebesar 11.402,52 ton. Potensi tanaman kelapa di Kabupaten Jember dimanfaatkan warga sebagai penghasil gula kelapa, meskipun hanya ada di dua kecamatan, yaitu kecamatan Wuluhan dan Tempurejo, meskipun dengan produksi yang relatif kecil. Meskipun demikian, usaha gula kelapa ini banyak dijadikan pengrajin sebagai mata pencaharian utama, dengan kontribusi sebesar $60 \%$ dari total pendapatan keluarga. Potensi kelapa yang besar di Kecamatan Wuluhan dimanfaatkan sebagian warganya sebagai pengrajin gula merah. Desa Lojejer merupakan desa yang memiliki pengrajin gula kelapa paling banyak, sehingga gula kelapa merupakan komoditas industri unggulan menurut desa, seperti nampak pada Tabel 2 berikut. 
Tabel 2. Komoditas Industri Unggulan Menurut Desa Tahun 2014

\begin{tabular}{clccc}
\hline \multirow{2}{*}{ No Desa } & & \multicolumn{3}{c}{ KomoditasIndustri Unggulan } \\
\cline { 3 - 5 } & & Genteng & Tempe/Tahu & Gula Kelapa \\
\hline 1 & Lojejer & 28 & - & 122 \\
2 & Ampel & 1 & - & 9 \\
3 & Tanjungrejo & 30 & - & - \\
4 & Kesilir & 1 & - & 37 \\
5 & Dukuh Dempok & 4 & - & - \\
6 & Tamansari & 220 & - & - \\
7 & Glundengan & 1 & - & $\mathbf{1 7 2}$
\end{tabular}

Sumber : Badan Pusat Statistik Jember (2015) Industri gula kelapa di Kecamatan Wuluhan termasuk dalam kelompok industri rumah tangga. Kendala yang banyak dihadapi industri ini adalah keterbatasan modal, akses pasar, teknologi, manajemen dan lain lain. Sebagai akibatnya, para pengrajin tidak banyak mempunyai inovasi baru, misalnya dalam hal standarisasi dan diversifikasi produk ataupun kemasan, sehingga nilai jual produk rendah dan sangat tergantung pada para tengkulak desa. Berdasarkan latar belakang dan perumusan masalah, maka tujuan penelitian adalah sebagai berikut: Untuk mengetahui saluran pemasaran industri rumah tangga gula kelapa tiap skala usaha, untuk mengetahui margin pemasaran industri rumah tangga gula kelapa tiap skala usaha, dan mengetahui efisiensi pemasaran industri rumah tangga gula kelapa tiap skala usaha.

\section{METODO PENELITIAN Metode Penelitian}

Metode yang digunakan dalam penelitian adalah metode deskriptif dan survey. Metode deskriptif yaitu suatu metode dalam meneliti status sekelompok manusia, suatu obyek, suatu kondisi, suatu sistem pemikiran atau suatu kelas peristiwa pada masa sekarang (Nazir, 1999).

\section{Penentuan Lokasi Penelitian dan Sampel}

Penentuan lokasi penelitian
(kecamatan) dilaksanakan secara sengaja (purposive method) di Kecamatan Wuluhan dengan pertimbangan bahwa kecamatan tersebut merupakan satu dari dua kecamatan yang mempunyai usaha industri pengolahan gula kelapa di Kabupaten Jember. Selanjutnya Penentuan sampel (responden) dilakukan secara non random sampling menggunakan metode Snow Ball Rolling (Penarikan sampel pola bola salju). Teknik Snow Ball Rolling yaitu penarikan sampel berdasarkan informasi dari sampel pertama demikian seterusnya sampai jumlah sampel itu di anggap cukup (Danim, 2000).

Sampel penelitian berjumlah 90 pengrajin gula kelapa yang dibagai dalam tiga skala usaha, yaitu skala kecil, menengah dan besar dengan ketentuan sebagai berikut:

a. Skala kecil: jumlah pohon yang dikelola $\leq 25$ pohon.

b. Skala menengah: jumlah pohon yang dikelola $26-50$ pohon.

c. Skala besar: jumlah pohon yang dikelola $>50$ pohon.

\section{Metode Analisis Data}

Metode analisis data yang digunakan untuk menguji hipotesis dalam penelitian ini adalah:

1. Untuk mengetahui saluran pemasaran gula kelapa pada tiap skala usaha dengan cara melakukan pengamatan dan wawancara langsung di lapang.

2. Untuk mengukur margin pemasaran menggunakan rumus (Sutarno, 2014):

$$
M P=\operatorname{Pr}-P f
$$

di mana:

MP = Margin Pemasaran

Pr $\quad=$ Harga di tingkat pengeceran

Pf = Harga ditingkat petani/pengrajin

3. Untuk mengukur efisiensi pemasaran digunakan indikator share harga dihitung dengan menggunakan rumus (Downey dan Erickson:1992 ): 
Share harga $=S p=$

$\frac{\text { Pf }}{P r} \times 100 \%$

Keterangan :

$\mathrm{Sp}=$ Bagian harga yang diterima produsen/pengrajin

$\mathrm{Pf}=$ Harga ditingkat produsen/pengrajin

$\mathrm{Pr}=$ Harga ditingkat konsumen

Kriteria pengambilan keputusan:

Jika Sp $\geq 40 \%$ berarti pemasaran gula kelapa bagi pengrajin adalah efisien.

Jika Sp $<40 \%$ berarti pemasaran gula kelapa bagi pengrajin adalah tidak efisien.

\section{HASIL DAN PEMBAHASAN Saluran Pemasaran}

Saluran pemasaran yang digunakan oleh pengrajin gula kelapa melalui beberapa pertimbangan yaitu harga jual, lembaga pemasaran, biaya pemasaran yang dikeluarkan, kapasitas produksi gula kelapa dan adanya jaminan pasar. Dengan adanya saluran pemasaran yang efisien akan menghasilkan harga yang sesuai baik pada tingkat produsen maupun konsumen, sehingga akan dapat memacu produsen untuk lebih giat dalam mengelola usaha gula kelapa tersebut.

Berdasarkan hasil penelitian dapat diketahui bahwa terdapat 3 (tiga) jenis saluran pemasaran yang dipilih oleh pengrajin gula kelapa untuk memasarkan hasil produksinya. Saluran pemasaran yang dipilih oleh para pengrajin gula kelapa di daerah penelitian adalah saluran pemasaran nol tingkat, satu tingkat dan tiga tingkat. Pada Gambar 1 menjelaskan mengenai macammacam saluran pemasaran gula kelapa yang terjadi di Kecamatan Wuluhan Kabupaten Jember.

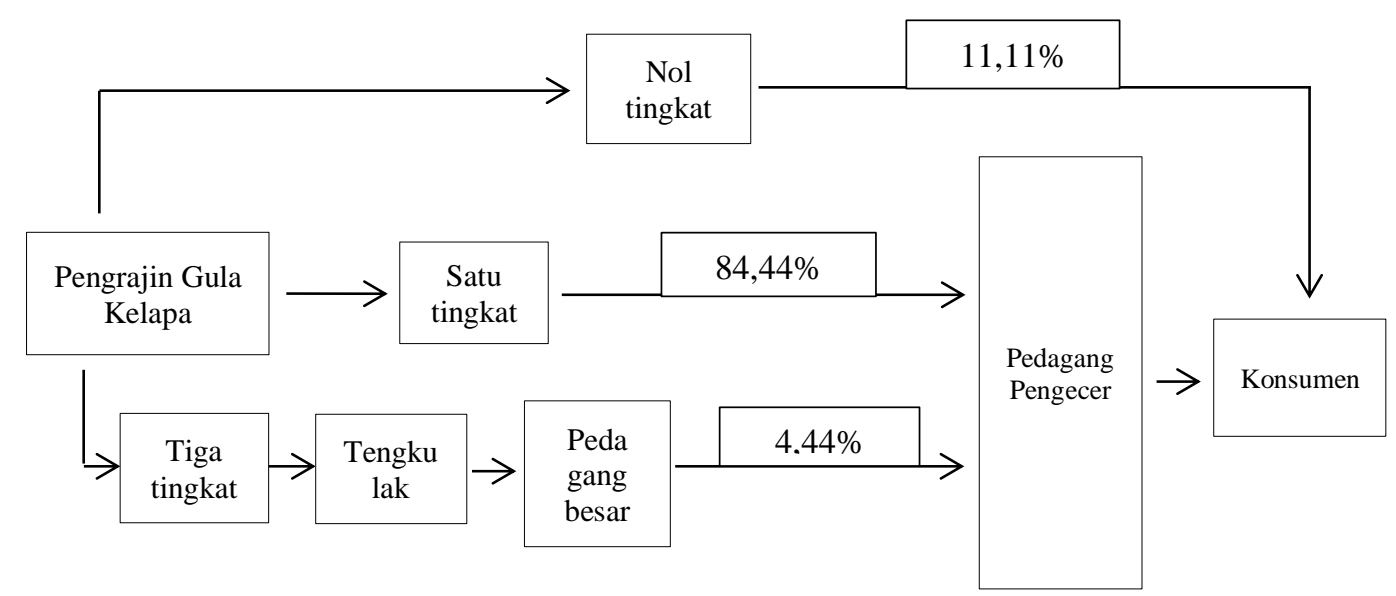

Gambar 1.Saluran Pemasaran Agroindustri Rumah Tangga Gula Kelapa di Kecamatan Wuluhan Kabupaten Jember, Tahun 2016

Penggunaan saluran pemasaran nol tingkat sebanyak $11,11 \%$ pengrajin gula kelapa, sedangkan saluran satu tingkat sebanyak $84,44 \%$ dan penggunaan pada saluran tiga tingkat sebesar $4,44 \%$.

\section{Saluran Pemasaran Nol Tingkat}

Saluran pertama adalah saluran pemasaran nol tingkat. Saluran pemasaran ini dinamakan saluran pemasaran nol tingkat karena tidak ada saluran pemasaran lain yang terlibat, pengrajin langsung ke konsumen akhir tanpa melalui lembaga pemasaran lain. Saluran pemasaran nol tingkat digunakan oleh 5 pengrajin yaitu pengrajin gula kelapa skala kecil dengan persentase 5,56\% pengrajin dari 90 pengrajin gula kelapa yang ada di Desa Lojejer Kecamatan Wuluhan.

Pengrajin yang menggunakan saluran ini adalah pengrajin gula kelapa dengan pengolahan pohon kelapa kurang dari 25 pohon, karena jumlah produksinya tidak banyak pemasarannya langsung ke konsumen. Pada pemasaran gula kelapa melalui saluran nol tingkat ini, pengrajin 
dengan harga jual sebesar Rp.9.059,-/kg. Untuk lebih jelasnya jenissaluran pemasaran yang digunakan oleh pengrajin gula kelapa berdasarkan skala terdapat pada Tabel 3 . berikut ini.

Tabel 3. Penggunaan Saluran Pemasaran Agroindustri Rumah Tangga Gula Kelapa di Kecamatan Wuluhan Kabupaten Jember, Tahun 2016

\begin{tabular}{ccccccc}
\hline \multirow{2}{*}{$\begin{array}{c}\text { Saluran } \\
\text { Pemasaran }\end{array}$} & \multicolumn{2}{c}{ Skala Besar } & \multicolumn{2}{c}{ Skala Menengah } & \multicolumn{2}{c}{ Skala Kecil } \\
\cline { 2 - 7 } & Jumlah & $\begin{array}{c}\text { Persentase } \\
(\boldsymbol{\%})\end{array}$ & Jumlah & $\begin{array}{c}\text { Persentase } \\
(\boldsymbol{\%})\end{array}$ & $\begin{array}{c}\text { Jumlah } \\
\text { Persentase } \\
(\boldsymbol{\%})\end{array}$ \\
\hline Nol Tingkat & - & - & - & - & 10 & 11,11 \\
Satu Tingkat & - & - & 63 & 70,00 & 13 & 14,44 \\
Dua Tingkat & - & - & - & - & - & - \\
Tiga Tingkat & 4 & 4,44 & - & 70,00 & 23 & 25,55 \\
\hline Jumlah & 4 & 4,44 & 63 & & - & - \\
\hline
\end{tabular}

Sumber: Hasil analisis data primer (2016).

\section{Saluran Pemasaran Satu Tingkat}

Saluran pemasaran kedua adalah saluran pemasaran satu tingkat, saluran pemasaran ini dinamakan saluran pemasaran satu tingkat karena proses penyaluran gula kelapa dari pengrajin ke konsumen melalui satu lembaga pemasaran yaitu pedagang pengepul atau tengkulak. Saluran pemasaran tingkat satu digunakan oleh 68 pengrajin dengan persentase $75,55 \%$ dari 90 pengrajin gula kelapa yang ada di desa lojejer Kecamatan Wuluhan. Pengrajin yang menggunakan saluran pemasaran ini adalah sebagian pengrajin gula kelapa skala kecil dan menengah dengan jumlah pohon kelapa berkisar 40-50 pohon dengan harga jual sebesar Rp. 9.500,-/kg.

\section{Saluran Pemasaran Tiga Tingkat}

Saluran yang terakhir adalah saluran pemasaran tiga tingkat karena gula kelapa dijual hingga sampai pada konsumen dengan melalui tiga lembaga pemasaran yaitu tengkulak, pedagang besar dan pengecer. Bentuk saluran pemasaran ini merupakan bentuk saluran pemasaran yang hanya digunakan oleh pengrajin gula kelapa skala besar untuk menyalurkan hasil produksinya. Harga jual dari pengrajin adalah Rp.10.925,$/ \mathrm{kg}$ dan harga yang dijual pengecer kepada konsumen sebesar Rp.12.500,-/kg.

\section{Margin Pemasaran Setiap Macam Saluran Pemasaran}

Margin pemasaran juga sebagai salah satu indikator efisiensi pemasaran, semakin rendah margin pemasaran maka semakin menguntungkan bagi konsumen dikarenakan harga jual yang murah.Hasil penelitian margin pemasaran pada masing-masing saluran pemasaran terdapat pada Tabel 4.

Tabel 4. Margin Pemasaran Pada Masing-Masing Pelaku Pasar dalam Saluran Pemasaran Agroindustri Rumah Tangga Gula Kelapa di Kecamatan Wuluhan Kabupaten Jember, Tahun 2016

\begin{tabular}{|c|c|c|c|c|c|c|}
\hline \multirow[b]{3}{*}{ Pelaku } & \multicolumn{6}{|c|}{ Saluran Pemasaran } \\
\hline & \multicolumn{2}{|c|}{ Tingkat Nol } & \multicolumn{2}{|c|}{ Tingkat Satu } & \multicolumn{2}{|c|}{ Tingkat Tiga } \\
\hline & $\begin{array}{c}\text { Harga } \\
\text { jual } \\
(\mathbf{R p} / \mathbf{k g})\end{array}$ & $\begin{array}{c}\text { Selisih } \\
\text { Harga } \\
\text { (Rp) } \\
\end{array}$ & $\begin{array}{c}\text { Harga } \\
\text { jual } \\
(\mathbf{R p} / \mathbf{k g}) \\
\end{array}$ & $\begin{array}{c}\text { Selisih } \\
\text { Harga } \\
\text { (Rp) }\end{array}$ & $\begin{array}{c}\text { Harga } \\
\text { jual } \\
(\mathrm{Rp} / \mathrm{kg}) \\
\end{array}$ & $\begin{array}{c}\text { Selisih } \\
\text { Harga } \\
(\mathbf{R p})\end{array}$ \\
\hline 1. Produsen/pengrajin & 9.059 & - & 9.500 & - & 10.925 & - \\
\hline 2. Pedagang Tengkulak & & & & & 11.500 & 575 \\
\hline 3. Pedagang besar & - & - & - & - & 11.950 & 450 \\
\hline 4. Pedagang Pengecer & - & - & 10.200 & 700 & 12.500 & 550 \\
\hline 5. Konsumen & 9.059 & - & 10.200 & - & 12.500 & - \\
\hline Margin Pemasaran & & 0 & & 700 & & 1.575 \\
\hline
\end{tabular}

Sumber: Hasil Analisis Data Primer (2016).

Pada saluran pemasaran nol tingkat tidak ada selisih harga jual pada pengajin/produsen gula kelapa dengan lembaga pemasaran lainnya, hal ini karena tidak ada lembaga pemasaran lain yang 
terlibat. Proses pemasaran gula kelapa langsung pada konsumen akhir yang mendatangi rumah pengrajin, hal inilahyang menyebabkan harga jual rendah. Harga jual pada pemasaran nol tingkat sebesar Rp.9.050,-.

Harga jual di tingkat produsen pada pemasaran satu tingkat sebesar Rp.9.500,-. Harga ini lebih tinggi dibanding harga jual saluran pemasaran nol tingkat karena pengrajin mengantar produknya kepada pedagang pengecer. Margin pemasaran pada saluran pemasaran satu tingkat sebesar Rp.700,-/kg.Hal ini karena ada satu lembaga pemasaran yang terlibat yaitu pedagang pengecer. Harga jual ditingkat produsen juga lebih tinggi dbandingkan dengan harga jual saluran nol tingkat.

Pada saluran pemasaran tiga tingkat harga jual ditingkat produsen sebesar Rp.10.925,- karena produsen mengantar produknya kepada tengkulak yang jaraknya lebih jauh dibanding pedagang pengecer pada saluran pemasaran satu tingkat sehingga pengrajin memerlukan biaya transportasi yang lebih banyak. Margin pemasaran sebesar Rp.1.575,-/kg karena ada tiga lembaga pemasaran yang terlibat, harga ditingkat produsen juga lebih tinggi dibandingkan saluran pemasaran lainnya.

Meskipun saluran pemasaran tiga tingkat mempunyai margin pemasaran yang besar namun tidak dapat dihindari, terutama untuk memenuhi permintaan konsumen yang lokasinya jauh dari tempat pengrajin. Berdasarkan hasil analisis ini jika dibandingkan dengan penelitian sebelumnya yaitu Utomo (2008) menunjukkan bahwa ditinjau dari segi ekonomis, saluran pemasaran gula kelapa dua tingkat di Kabupaten Kulon Progo paling efisien karena margin pemasarannya paling rendah dibandingkan dengan saluran pemasaran tiga tingkat dan satu tingkat.

\section{Efisiensi Pemasaran Pada Setiap Saluran Pemasaran \\ Efisiensi pemasaran diukur dari share} harga yang diterima pengrajin/produsen, semakin tinggi nilai share harga maka semakin efisien. Share harga adalah ratio antara harga yang diterima produsen dengan harga yang dibayarkan konsumen. Guna melihat tingkat efisiensi pemasaran pada setiap saluran pemasaran di Kecamatan Wuluhan Kabupaten Jember terdapat pada Tabel 5 berikut.

Tabel 5. Efisiensi Pemasaran pada Setiap Saluran Pemasaran Agroindustri Rumah Tangga Gula Kelapa di Kecamatan Wuluhan Kabupaten Jember, Tahun 2016

\begin{tabular}{ccrrrr}
\hline No & Saluran Pemasaran & $\begin{array}{c}\text { Harga } \\
\text { tingkat } \\
\text { produsen } \\
(\mathbf{R p} / \mathbf{k g})\end{array}$ & $\begin{array}{c}\text { Harga } \\
\text { tingkat } \\
\text { konsumen } \\
(\mathbf{R p} / \mathbf{k g})\end{array}$ & $\begin{array}{c}\text { Margin } \\
\text { Pemasaran } \\
(\mathbf{R p} / \mathbf{k g})\end{array}$ & $\begin{array}{c}\text { Share Harga } \\
\text { Produsen } \\
(\%)\end{array}$ \\
\hline 1. & Saluran pemasaran nol tingkat & 9.059 & 9.059 & 0 & 100 \\
2. & Saluran pemasaran satu tingkat & 9.500 & 10.200 & 700 & 93,13 \\
3. & Saluran pemasaran tiga tingkat & 10.925 & 12.500 & 1.575 & 87,40 \\
\hline
\end{tabular}

Sumber : Hasil analisis data primer (2016).

Berdasarkan hasil perhitungan Tabel 5 didapatkan hasil bahwa share harga ditingkat pengrajin saluran pemasaran nol tingkat adalah sebesar $100 \%$, artinya seluruh harga yang dibayar konsumen sepenuhnya dinikmati oleh pengrajin. Pada saluran pemasaran satu tingkat share harga sebesar $93,13 \%$, artinya 93,13\% dari harga yang dibayar oleh konsumen dinikmati oleh pengrajin.Share harga pada saluran pemasaran tiga tingkat adalah 87,40\%, artinya $87,40 \%$ dari harga yang dibayar oleh konsumen tersebut dinikmati oleh pengrajin. Share harga dari ketiga saluran pemasaran menunjukkan hasil lebih dari 40\%. Menurut Downey dan Erickson (1992) jika share harga $\geq 40 \%$ maka saluran pemasaran dikatakan efisien. Berdasarkan hal tersebut maka saluran pemasaran gula kelapa di Kecamatan Wuluhan Kabupaten Jember termasuk dalam kategori efisien. Meskipun kriteria efisiensi pemasaran pada penelitian yang dilakukan oleh Hadi (2016) dan Bisuk 
(2009) yang didasarkan oleh pendapat Gultom (1996) adalah $\geq 50 \%$.

Ketiga saluran pemasaran gula kelapa di Kecamatan Wuluhan, saluran nol tingkat merupakan saluran pemasaran dengan harga jual kepada konsumen paling rendah, namun konsumen harus membeli langsung kepada pengrajin. Konsumen yang tempat tinggalnya jauh dari tempat tinggal pengrajin tidak mungkin menggunakan saluran pemasaran nol tingkat karena biaya transportasi kerumah pengrajin jauh lebih mahal daripada harga jual pada saluran pemasaran tiga tingkat. Hal ini menunjukkan bahwa saluran pemasaran nol tingkat tidak selalu paling baik dan saluran pemasaran panjang tidak selalu paling buruk tergantung pada banyak hal, antara lain: jarak antara konsumen dan produsen, keterlibatan lembaga pemasaran, dan jumlah produk yang akan dipasarkan.

Pengrajin skala besar yang menghasilkan gula merah dalam jumlah banyak tidak mungkin hanya menggunakan saluran pemasaran nol tingkat untuk memasarkan seluruh produknya. Seluruh sampel pengrajin skala besar menggunakan saluran pemasaran tiga tingkat karena hanya pedagang tengkulak dari luar kota bermodal besar yang mampu membeli seluruh produk yang dihasilkan setiap hari. Sementara pengrajin skala menengah dapat menggunakan saluran pemasaran nol atau satu tingkat asal dapat menjual seluruh produk yang dihasilkan setiap hari.

Berdasarkan hasil analisis ini jika dibandingkan dengan penelitian sebelumnya yang diilakukan oleh Utomo (2008) dalam kajian pada produk yang sama menunjukkan bahwa share harga paling tinggi terdapat pada saluran pemasaran dua tingkat sebesar $86,7 \%$. Hal ini karena harga jual ditingkat produsen dan ditingkat pedagang tidak berbeda jauh.

\section{KESIMPULAN}

Berdasarkan hasil analisis data dan pembahasan tentang analisis pemasaran agroindustri rumah tangga gula kelapa di
Kecamatan Wuluhan Kabupaten Jember dapat disimpulkan bahwa:

1. Ada tiga macam saluran pemasaran gula kelapa, yaitu: 1) saluran pemasaran nol tingkat digunakan oleh $11,11 \%$ pengrajin yang seluruhnya merupakan dari skala kecil, 2) saluran satu tingkat digunakan oleh $84,44 \%$ pengrajin, terdiri dari penrgajin skala kecil dan menengah, 3) saluran tiga tingkat digunakan oleh 4,44\% pengrajin, seluruhnya merupakan pengrajin skala besar.

2. Margin pemasaran terendah terdapat pada saluran pemasaran nol tingkat yaitu Rp.0,-/kg, tertinggi pada saluran pemasaran tiga tingkat sebesar Rp.1.575,-/kg, sedangkan pada saluran pemasaran satu tingkat, Rp.700,-/kg.

3. Seluruh saluran pemasaran yang digunakan efisien, tercermin dari share harga yang lebih besar dari 40\%. Share harga pengrajin tertinggi terdapat pada saluran pemasaran nol tingkat sebesar $100 \%$, terendah pada saluran pemasaran tiga tingkat sebesar $87,40 \%$, sedangkan pada saluran pemasaran satu tingkat sebesar 93,13\%.

\section{DAFTAR PUSTAKA}

Bisuk, P. 2009. Analysis of Trading and Elasticity of International $\mathrm{CPO}$ Price Transmission on FFB Price (Fresh Fruit Bunch) of Palm Oil (Case Study: Mananti Village, Sosa Sub-district, Padang Lawas Regency). Essay. Faculty of Agriculture USU. Field. Http: // repository.usu.ac.id. Downloaded on February 09, 2014.

BPS Kabupaten Jember, 2015. Kecamatan Wuluhan dalam Angka 2014. Kantor Biro Pusat Statistik Jember.

Danim, S. 2000. Metode Penelitian Untuk Ilmu-ilmu Perilaku. Bumi Aksara. Jakarta. 
Downey, W.B dan Erickson. 1992. Manajemen Agribisnis. Penerbit: Erlangga. Jakarta.

Hadi, S., Sutiarso, E., Awaluddin, A., dan Herlambang, T., 2017. Implementation of Hygienic Fish Market Model and Its Implication on Market Structure and Marketing Efficiency of Sea Fish in Jember Regency. Prosiding on The International Conference on Food Sovereingnty and sustainable agriculture (FOSSA-2017) by Faculty of Agrikulture, Jember University, Indonesia, August 01 03, 2017. ISBN: 978-602-61803-46
Nazir, M. 1999. Metode Penelitian, Ghalia Indonesia. Jakarta.

Sutarno. 2014. Analisis Efisiensi Pemasaran Kedelai di Kabupaten Wonogiri. eJournal Agrineca. 14 (1): 1-10.

Utomo. 2008. Analisis Pemasaran Gula Kelapa di Kabupaten Kulon Progo. Skripsi. Universitas Sebelas Maret. Surakarta. 